East Tennessee State University

Digital Commons @ East Tennessee State University

\title{
Best Practices for New Online Management Education Instructors to Overcome Resistance to Online Teaching: New Insights
}

Lorianne D. Mitchell

East Tennessee State University, mitcheld@etsu.edu

Follow this and additional works at: https://dc.etsu.edu/etsu-works

Part of the Business Administration, Management, and Operations Commons, Higher Education Commons, and the Online and Distance Education Commons

\section{Citation Information}

Mitchell, Lorianne D.. 2020. Best Practices for New Online Management Education Instructors to Overcome Resistance to Online Teaching: New Insights. Handbook o+6468:6577f Teaching with Technology in Management, Leadership, and Business. Research Handbooks in Business and Management series. Stuart Allen, Kim Gower, and Danielle K. Allen, Eds. Edward Elgar Publishing. ISBN: 9781789901658 


\section{Best Practices for New Online Management Education Instructors to Overcome Resistance to Online Teaching: New Insights}

\section{Copyright Statement}

This is a draft chapter/article. The final version will be available in Handbook of Teaching with Technology in Management, Leadership, and Business edited by Stuart Allen, Kim Gower, and Danielle K. Allen, forthcoming September 2020, Edward Elgar Publishing Ltd.

The material cannot be used for any other purpose without further permission of the publisher, and is for private use only. 


\title{
Best Practices for New Online Management Education Instructors to Overcome Resistance to Online Teaching: New Insights
}

\author{
Lorianne D. Mitchell
}

Enrollment in online courses has increased rapidly in the last two decades, and exponentially in the last few years (Seaman, Allen, \& Allen, 2018) as part of an e-revolution, especially in business schools (Kumar, Kumar, Palvia, \& Verma, 2019), in which access to and use of information technology has become widespread. Instructors are one of the most important variables in online teaching as they function as the source of content for, and facilitators of, the online course. Some faculty, however, are ambivalent about teaching online for a variety of reasons (Mitchell, Parlamis, \& Claiborne, 2015), and this ambivalence can be the impetus for the failure of the online course implementation. In addition, although research ("No significant difference", n.d.) demonstrates that learning in online classes is comparable to learning in onground courses, instructors' attitudes toward online teaching remain divided.

In this chapter, I offer a brief review of Mitchell et al. (2015) and its general recommendations for management educators to help overcome their resistance to online teaching. I then expand upon what was previously written by sharing specific recommendations and resources focused on faculty, and for administrators to use with faculty, as they attempt the change to online teaching. To this end, I begin with a discussion of the notion of fit in the context of selecting faculty with a particular set of characteristics that are best suited to teaching online courses. The next portion of the chapter offers a research-derived list of best practices for new online instructors - addressing both hard and soft issues. Next, the discussion continues with a brief review of additional factors pertinent to teaching online but not included in the previous 
list. This will include topics gleaned both from research and over a decade and a half of personal online and hybrid experience as a management educator.

\section{Brief Review of Previous Literature}

In the inspiration for this chapter (Mitchell et al., 2015), the authors addressed the ambivalence their audience (management education faculty) sometimes experience when facing the change from teaching in a traditional classroom environment to teaching online or via the internet. After giving a brief history and then identifying faculty as central to the planned change towards online learning, Mitchell et al. proposed four common sources of faculty resistance to teaching online: 1) cultural assumptions and values; 2) fears of the unknown, loss, and failure; 3) fear of disruption of interpersonal relationships; and 4) concerns about the external impact. The authors then identified an individual-level framework for addressing resistance to this unique type of change, one that differed from others used previously for change driven by the organization, rather than driven by the individual, namely, the Transtheoretical Model of Change (TTM; Prochaska, Redding, \& Evers, 2008).

The TTM lays out a framework consisting of three interrelated dimensions: temporal (includes 6 stages that specify when to change), cognitive-behavioral (contains 10 processes that specify how to change - cognitively, emotionally and behaviorally), and individual difference (considerations of individuals' decisional balance and self-efficacy when making the change decision) and, fundamentally posits that these three dimensions must be addressed interactively for change to occur (Prochaska, Redding, \& Evers, 2008). As a result, the Mitchell et al. (2015) article was unique in that it proposed ways to overcome faculty avoidance to teaching online including: a) giving voice to the concerns some faculty have regarding teaching online (Kumar et al., 2019); b) placing faculty squarely at the core of the effort to increase and improve online 
learning; and c) proposing an existing framework (TTM) used traditionally for changing individual behavior. TTM can be adapted and adopted to provide direction and assist in overcoming personal factors contributing to faculty ambivalence or resistance (Table 1).

\section{Table 1.}

TTM-based Recommendations for Faculty

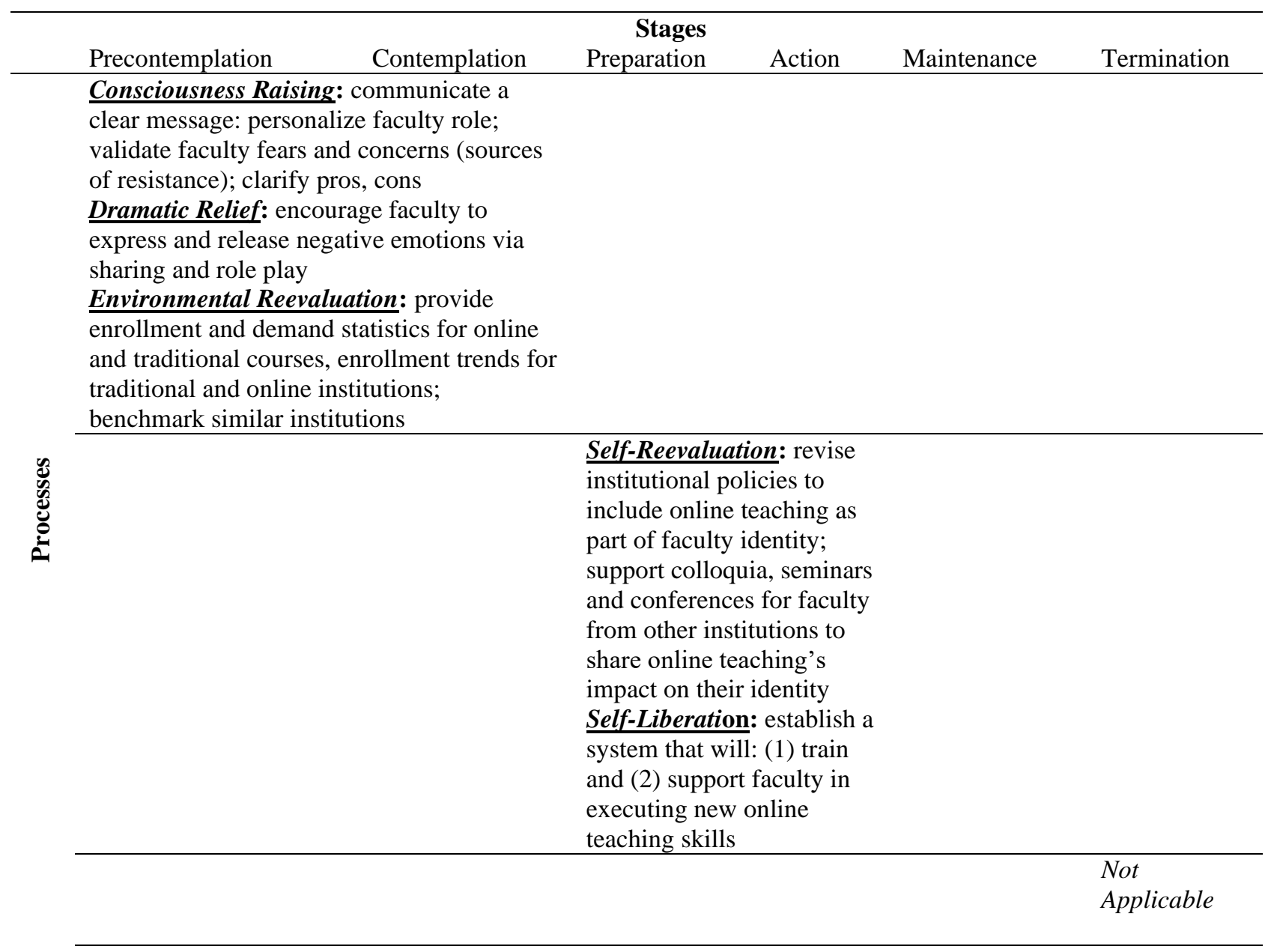

Notes. Table from Mitchell et al. (2015). Reprinted with permission from SAGE Publications.

The first three process recommendations by Mitchell et al. (2015) primarily address creating faculty readiness for change during the precontemplation and contemplation stages of the temporal dimension of TTM (Prochaska, Redding, \& Evers, 2008). These include: 1) engaging faculty in consciousness raising (e.g., a list of pros and cons of online teaching) by validating their fears and concerns; 2) engaging faculty in dramatic relief, such as through the 
sharing of their concerns about online education (or by taking an online course themselves), to help release some of their negative perceptions of online teaching; and 3) engaging faculty in environmental-reevaluation such as by the sharing of enrollment trends and data regarding the high demand for online classes (Mitchell et al., 2015). There is a preponderance of research evidence supporting each of these three recommendations - especially the third one, as summarized in the introduction of this chapter. Therefore, it is the onus of administrators to gather and present said evidence to faculty before proceeding to the next stages of change.

The latter three process recommendations, outlined below, occur in the preparation and action stages of TTM (Prochaska, Redding, \& Evers, 2008) and pertain to faculty readiness to change. These recommendations are: 4) assisting faculty in self-reevaluation so that online teaching becomes a natural part of the visualization of what it means to be a professor; 5) assisting faculty in the self-liberation process by establishing a system that imparts new skills via the training of new online faculty; and 6) assisting faculty in the self-liberation process by continually supporting new online faculty in exercising their increased self-efficacy (Mitchell et al., 2015).

Each of the proceeding sections will be framed loosely within the context of these six TTM-based recommendations - but with a greater focus on the three preparation and action recommendations.

\section{Personal Characteristics and Behaviors of Successful Online Faculty}

The topic of personal characteristics was introduced in the Mitchell et al. (2015) article in reference to recommendations for the self-liberation process - specifically, self-efficacy. However, personal characteristics may also play a part in recommendations 1) through 5). 
Self-efficacy. One personal characteristic is self-efficacy - particularly computer-selfefficacy overall (Dunbar \& Melton, 2018) or self-efficacy with the chosen online learning management system (e.g., Canvas, D2L, Blackboard) through which the course is administered (Zheng et al., 2018). Veteran online faculty often have developed high self-efficacy in this domain; however, Dunbar and Melton (2018) reported that receiving further training in seminars, workshops, and courses increased faculty confidence in their ability to use the computer to administer courses, resulting in the development of higher quality courses and improved student learning. Faculty self-efficacy also increased when instructors perceived organizational support for online learning (Zheng et al., 2018).

Self-disclosure. One behavior in which successful online faculty engage is self-disclosure - in the context of increasing students' perception of the instructor's online social presence, which in turn leads to increased perceptions of learning acquisition (Song, Kim, \& Park, 2019). To increase social presence through self-disclosure veteran online management educators participate in online discussion boards. For instance, in the beginning of the term, an instructor can post a brief introductory video message. In this message, the instructor may share personal or professional information with students such as their educational background, research interests, and hobbies. Students like to discover who their professors are as individuals - that they are human also. The instructor may also then comment on each individual student's initial discussion thread, welcoming the student to the course and commenting on, or asking a question about, something distinctive in the student's post. This demonstrates that the instructor reads every student's post and makes each student feel seen as an individual.

Another example of self-disclosure is for the instructor to share personal examples as they apply to course material. For instance, while discussing the subject of conflict the instructor 
may share conflicts he or she experienced in a previous career or leadership role. Or, the instructor may share personal experiences during his or her travels while discussing ethnocentrism and globalization.

\section{Best Practices for New Online Management Education Faculty}

An initial search of most research databases and Internet sources yields multiple results for online course development checklists. Nonetheless, many schools offering online classes have yet to establish and enforce the use of a robust set of standards for online course creation (e.g., Quality Matters standards). In fact, like many veteran online instructors, I was never offered any formal training on how to correctly develop an online course before teaching my first one many years ago. As a proven effective on-ground instructor, I was offered the opportunity to teach online but was required to quickly get a course 'up and running', so I hastily converted my on-ground course materials to an online format. It was not until later, through an informal system of trial-and-error and independently seeking out workshops and attending academic conference sessions, that I improved my online courses year after year. A few years later, the university began offering a yearlong course on how to effectively teach online. However, due to limited funding and other institutional resources, only two faculty members from each department were accepted into the course each year.

As many new online faculty soon discover, simply uploading on-ground course materials to an online learning management system is not the best way to approach online teaching. Rather, effective online instruction requires considerations that vary significantly from traditional on-ground education (Baldwin \& Ching, 2018). Existing resources to help guide the novice online instructor are often either developed by course design professionals or other online instructors (see Baldwin \& Ching, 2018 for a more comprehensive discussion). However, the 
faculty member new to online teaching may become easily overwhelmed by the abundance of results from an online search for an online course development checklist.

To this end, Baldwin and Ching (2018) reviewed the empirical literature on online course development, as well as current (created after 2010) checklists with widespread influence, in order to design, develop and test the Online Course Design Checklist (OCDC, henceforth). The OCDC is not meant to be all-inclusive but instead to "encourage course designers to include practices that have the most impact and also the items that may be overlooked" (p. 163). The result is a tool that study participants liked because it is a concise, research-based, simple-to-use checklist that covers most, if not all, of the basic items new online faculty should consider (Baldwin \& Ching, 2018).

Table 2. Online Course Design Checklist

\begin{tabular}{|c|c|c|}
\hline Before & During & After \\
\hline $\begin{array}{l}\text { Analyze learners to understand their } \\
\text { knowledge }\end{array}$ & $\begin{array}{l}\text { Chunk information into manageable } \\
\text { lessons }\end{array}$ & $\begin{array}{l}\text { Confirm course tasks measure what } \\
\text { you want students to learn }\end{array}$ \\
\hline $\begin{array}{l}\text { Identify what will be covered in the } \\
\text { lesson }\end{array}$ & $\begin{array}{l}\text { Provide expectations regarding } \\
\text { quality of participation }\end{array}$ & $\begin{array}{l}\text { Eliminate extraneous media and } \\
\text { information }\end{array}$ \\
\hline $\begin{array}{l}\text { Identify measurable learning } \\
\text { objectives for students to accomplish }\end{array}$ & $\begin{array}{l}\text { Trigger interaction between } \\
\text { student-student, student-instructor, } \\
\text { student-content }\end{array}$ & $\begin{array}{l}\text { Check that lesson navigation is } \\
\text { intuitive for desktop/laptop/mobile } \\
\text { student }\end{array}$ \\
\hline & $\begin{array}{l}\text { Facilitate learning and engagement } \\
\text { through technology }\end{array}$ & Confirm all course links work \\
\hline & $\begin{array}{l}\text { Build community through } \\
\text { communication and activities }\end{array}$ & Run spell-check \\
\hline & Provide rubrics for assignments & $\begin{array}{l}\text { Have peer/friend/colleague review } \\
\text { work and identify unclear material }\end{array}$ \\
\hline & $\begin{array}{l}\text { State expectations for course } \\
\text { behavior }\end{array}$ & \\
\hline & $\begin{array}{l}\text { Include opportunities for students to } \\
\text { offer feedback on lesson format and } \\
\text { content }\end{array}$ & \\
\hline & Accommodate for disabilities & \\
\hline & $\begin{array}{l}\text { Provide contact information for } \\
\text { instructor, technology help and } \\
\text { student support services }\end{array}$ & \\
\hline
\end{tabular}

Notes. OCDC from Baldwin \& Ching (2018). 10.7 v22 Downloaded September 9, 2019 from https://sites.google.com/view/onlinecoursedesignchecklist/home. Reprinted with permission. 
There are 19 total items included in the latest 2019 OCDC version (Table 2) and those items are subdivided into three categories according to when they should be addressed in the online course design process. There are three items included for consideration prior to designing the course in the before-course-design phase, 10 items for the during-course-design phase, and six items for the after-course-design phase. To expand upon the OCDC, following are some examples for some of the items in each phase of the checklist.

One item in the 'before course' checklist is "identify measurable learning objectives for students to accomplish" (Baldwin \& Ching, 2018, p. 161). Course learning objectives should be included not only in the course syllabus, but also on the course website or the online course learning management system so students are clear on the goals they are striving to reach through their coursework.

Another item in the 'before course' checklist is "analyze learners to understand their knowledge base" (Baldwin \& Ching, 2018, p. 161). Instructors can administer a pre-test (or multiple-choice online quiz facilitated and scored by the learning management system) of all course content material at the very beginning of the course to assess students' knowledge baseline and to demonstrate to students what they do not know about the subject matter. This also helps demonstrate the value of taking the course. If a final examination or post-test is administered at the end of the term, containing similar questions to those used on the pre-test, students will clearly see their knowledge acquisition progress in the course.

One item in the 'during course' phase of the checklist is "provide rubrics for assignments" (Baldwin \& Ching, 2018, p. 161). Instructors should clearly explain the specific criteria for assessing each assignment. For example, an online discussion assignment rubric may include examples of what constitutes a 'good', 'better', and 'best' level posting. This should be 
both qualitative (what information should the posting include) as well as quantitative (how many

points are associated with each level of posting). The objective is that students should be clear on how assignments are graded in the course and how their submission corresponds to their grade.

Another item in the 'during course' phase of the checklist is "build community through communication and activities" (Baldwin \& Ching, 2018, p. 161). One way to 'build community' is to require students to respond to the discussion posts of at least two other classmates so that they are interacting with other members of the learning community. Another way is to pair students in the beginning of the course so they can become acquainted with each other and then have them introduce each other in a way other than in a discussion post (e.g., via video, slideshow, or song). Yet another way to build community is to assign students to teams to work on graded assignments.

One item in the 'after course' section of the OCDC is "confirm course tasks measure what you want students to learn", which may be accomplished by another checklist item "have peer/friend/colleague review work and identify unclear material” (Baldwin \& Ching, 2018, p. 161). New online instructors may approach a veteran instructor or a subject matter expert willing to review their course material for relevance. Busywork, or meaningless tasks that take up students' time without improving their course-related knowledge, should be eliminated from the course syllabus as required assignments. Additionally, assignments or tasks that fail to fully measure learning objectives should be revised until the individual reviewing the material deems it acceptable.

\section{Other Considerations When Teaching Management Online}

Experienced or veteran online management education faculty may recommend other approaches to assist with teaching online. These may include administering a mandatory 
assessment of resource materials at the beginning of the course, incorporating experiential learning, and ensuring ongoing engagement.

\section{Include a Mandatory Course Orientation Quiz}

One consideration for either the 'before course' or the 'during course' phase is to incorporate a mandatory quiz for all students - a simple 10-item assessment of elements students tend to overlook, become confused about, or just get wrong. The simple act of incorporating a quiz ensures that students review the course materials (e.g., syllabus, syllabus attachment, instructor's introductory video, writing style guide, key library resources) thoroughly and therefore know where to obtain information without depending on faculty to do an overabundance of hand-holding (see Table 3 for examples of quiz items).

\section{Table 3.}

Sample Items for a Course Orientation Quiz

1. On average, I may expect a response to an email/voicemail I sent to the instructor within (Multiple Choice)

2. I am required to take the online quizzes/examinations in a campus computer lab so the exam may be proctored. (T/F)

3. The official last day of the semester for the 15-Week Session of the Fall 2020 semester is (Multiple Choice)

4. If I miss an assignment, I have 24 hours from the deadline to contact the instructor to request an opportunity to make up the assignment. (T/F)

5. According to the University Honor Code, if I know of someone engaging in academic dishonesty, I should (Multiple Choice)

6. All assignment due dates and deadlines are for the time zone. (Multiple Choice)

7. The highest grade $I$ can earn in this course is an $A+$. (T/F)

8. If I have a disability, I should contact to get the necessary documents to ensure I have appropriate accommodations for optimal learning. (Multiple Choice)

9. If I earn less than a perfect score on this Course Orientation quiz . (Multiple Choice)

10. On (D2L/Canvas/Blackboard), I can find assignment rubrics (guidelines/criteria of how each assignment will be graded) by . (Multiple Choice)

11. I must visit my chosen business for Assignment \#2 by Week Choice)

12. On (D2L/Canvas/Blackboard), I can find the video tutorial on using correct APA writing style by . (Multiple Choice) 
The Course Orientation quiz may be administered and auto-scored via the course's learning management system, which also can provide instant feedback on their responses. Students can have unlimited attempts to obtain a perfect score; however, only the syllabus and the quiz will be visible to students until they obtain a perfect score. All other areas of the online course can be hidden under this special condition (sometimes called adaptive release or a similar term in learning management systems).

\section{Incorporate Experiential Learning}

Regardless of the nature of the course subject matter, an often-missing element in online courses more commonly found in on-ground courses is experiential learning (Kolb, 1984). This factor may be included in the 'during course' phase of online course development. Online faculty should ensure that students are not just passive learners in the course. Instead, management educators can design assignments that require students to actively interact with their environment, community, each other, and the instructor. For example, students may be required to compose a discussion thread about an interview with someone in their desired career field, an observation of a course trial, a visit to a business site, or a question and answer session with a guest speaker at a corporate event identified by the instructor.

Faculty who are very technologically savvy may even opt to create a social media page for students to share their experiences with the course material or for the purposes of a specific assignment. Instructors may then share relevant course content with students via the social media page. A note of caution here, however, is to assess the level of technological proficiency of students so as not to cause undue anxiety related to having to learn a new form of technology. 
Case-based learning and the use of games or simulations are other ways to introduce experiential learning (Mackavey \& Cron, 2019).

\section{Ensure Ongoing Student Engagement}

It is critical to not allow one's course to be on a somewhat of an autopilot mode because students may become disengaged and easily left behind. This may be even more true for students new to online courses, or those enrolled in both online and on-ground courses concurrently in the same academic term. In fact, many students are grateful for the regular direct communication from faculty and report that the online course could effortlessly become 'out of sight and out of mind'. A good practice may be to communicate regularly with students (e.g., a weekly announcement or email reminder to the entire class) about upcoming tasks and or assignments. Instructors may also share trends in successes and challenges they see in students' assignments (e.g., address correct APA citation if identified as a challenge to students). Faculty should regularly review the online course gradebook and students' login activity to identify at-risk students who may benefit from additional, more personalized communication. This factor may also be included in the 'after course' phase.

In addition to top-down engagement between the online instructor and students, instructors should also encourage students' ongoing engagement with classmates. For example, asynchronous online discussion board assignments, found to be predictors of academic performance (Galikyan \& Admiraal, 2019), can be assigned throughout the course term. In these graded assignments, students may discuss their results on self-assessments (e.g., personality tests), the key points in an online video (e.g., TedTalk), or related current events item. Moreover, instructors can require students' initial post to include a question to readers that will encourage additional conversation. Students should be required to respond to a minimum number of 
classmates per week, and, if possible, different classmates each week. This will ensure that there is interaction with as many classmates as possible and that friends do not automatically just respond to each other's discussion posts.

\section{Conclusion}

A perusal of fall 2019 articles in publications chronicling higher education (e.g., Piper, 2019) will highlight the sharp downward trend in overall enrollment across colleges and universities nationwide. However, the paradoxical upward trend in online course demand and enrollment creates a need for better online course development and teaching standards.

Researchers continue to make strides in addressing some of the personal factors that indicate and support faculty readiness to embrace teaching online.

High levels of self-efficacy and self-disclosure were highlighted as key in how instructors can navigate online teaching technology and are willing and able to foster a satisfactory studentteacher relationship. Further training and organizational support should improve the likelihood of online teaching success and increase the quality of online courses and student learning.

Finally, whether self-selected or recruited, novice or veteran, online faculty may reference the user-friendly checklist of the OCDC (Baldwin \& Ching, 2018) to improve the quality of their online course and increase the likelihood of high student achievement. They may also consider additional recommendations included in this chapter: 1) include a mandatory course orientation quiz; 2) incorporate experiential learning; and 3) actively ensure ongoing student engagement. In fact, some of the suggestions to incorporate experiential learning, such as the uses of case studies, simulations, and gamification (discussed in other chapters of this book in greater detail), may also further increase student engagement. Taken together, these 
recommendations may help the new online management educator form the foundation for a successful online teaching experience for both instructor and student. 


\section{References}

Allen, I. E., \& Seaman, J. (2016). Online report card: Tracking online education in the United States. Babson Park, MA: Babson Survey Research Group.

Baldwin, S. J., \& Ching, Y. H. (2019). An online course design checklist: Development and users' perceptions. Journal of Computing in Higher Education, 31(1), 156-172.

Dunbar, M., \& Melton, T. D. (2018). Self-efficacy and training of faculty who teach Online. In Hodges C. (Ed.), Self-Efficacy in Instructional Technology Contexts (pp. 15-33). Cham, Switzerland: Springer.

Galikyan, I., \& Admiraal, W. (2019). Students' engagement in asynchronous online discussion: The relationship between cognitive presence, learner prominence, and academic performance. The Internet and Higher Education, 43, 100692.

Kolb, D. A. (1984). Experiential Learning. Englewood Cliffs, NJ: Prentice-Hall.

Kumar, P., Kumar, A., Palvia, S., \& Verma, S. (2019). Online business education research: Systematic analysis and a conceptual model. The International Journal of Management Education, 17(1), 26-35.

Mackavey, C., \& Cron, S. (2019, May). Innovative strategies: Increased engagement and synthesis in online advanced practice nursing education. Nurse Education Today, 76, 8588.

Mitchell, L. D., Parlamis, J. D., \& Claiborne, S. A. (2015). Overcoming faculty avoidance of online education: From resistance to support to active participation. Journal of Management Education, 39(3), 350-371.

No significant difference. (n.d.). National Research Center for Distance Education and Technological Advancements. Retrieved from https://nosignificantdifference.org 
Piper, J. (2019, December 16). Enrollment dropped 1.3\% this fall from a year ago. But not every state tells the same story. The Chronicle of Higher Education. Retrieved from https://www.chronicle.com/article/Enrollment-Dropped-13-This/247719

Prochaska, J. O., Redding, C. A., \& Evers, K. E. (2008). The transtheoretical model and stages of change. In R. Glanz \& K. Viswanath (Eds.), Health behavior and health education: Theory, research and practice (4th ed., pp. 97-117). San Francisco, CA: Josey Bass.

Richardson, J. C., \& Swan, K. (2003). Examining social presence in online courses in relation to students' perceived learning and satisfaction, Journal of Asynchronous Learning Networks, 7(1), 68-88.

Seaman, J. E., Allen, I. E., \& Seaman, J. (2018). Grade increase: Tracking distance education in the United States. Babson Park, MA: Babson Survey Research Group.

Song, H., Kim, J., \& Park, N. (2019). I know my professor: Teacher self-disclosure in online education and a mediating role of social presence. International Journal of HumanComputer Interaction, 35(6), 448-455.

Zheng, Y., Wang, J., Doll, W., Deng, X., \& Williams, M. (2018). The impact of organisational support, technical support, and self-efficacy on faculty perceived benefits of using learning management system. Behaviour \& Information Technology, 37(4), 311-319. 